\title{
Disseminated neuroendocrine neoplasm with undetected primary tumor
}

Frederico Becker Ribeiro ${ }^{a}$, Sheila Aparecida Coelho Siqueira ${ }^{a}$ Marianne de Castro Gonçalves ${ }^{a}$, Anderson da Costa Lino Costa ${ }^{a}$

Ribeiro FB, Siqueira SAC, Gonçalves MC, Costa ACL. Disseminated neuroendocrine neoplasm with undetected primary tumor. Autopsy Case Rep [Internet]. 2012;2(3):13-20. http://dx.doi.org/10.4322/acr.2012.021

\section{ABSTRACT}

\begin{abstract}
Since the $19^{\text {th }}$ century, neuroendocrine neoplasms (NEN) have been identified. Right up to the present day, the nomenclature is still under debate reflecting the heterogeneity of these tumors. Although some of them are slow growing, some can be fearfully aggressive and may develop in almost any organ of the abdomen, thorax, neck, skin, and gonads. The most commonly observed sites of NEN are the lung and the gastroenteropancreatic system (GEP), where more than 50 entities have been observed. In case of a NEN of unknown primary tumor, the histopathological diagnostic workup includes immunohistochemistry for chromogranin A and synaptophysin, followed by specific tissue markers. Clinical presentation is very diverse, depending on the primary site and functionality of the tumor. In the case of the GEP-NEN, the main symptoms are abdominal pain, diarrhea, weight loss, gastrointestinal bleeding, or bowel obstruction. The presence of neuropsychiatric symptoms is not insignificant in this group of tumors. The authors report a case of a 51-year-old man who sought medical attention because of a three-month history of a consumptive disease. The diagnostic workup disclosed a diffuse nodular infiltration of the lungs, hypokalemia, and hypercalcemia in a cachectic patient. The clinical investigation could not proceed because of an infectious intercurrence, which led to the fatal outcome. Autopsy findings showed a diffuse metastatic NEN. The primary tumoral site could not be demonstrated with the available immunohistochemical panel.
\end{abstract}

Keywords: Neuroendocrine tumor; Neoplasms, unknown primary; Neoplasms, metastasis; Diarrhea; Cachexia.

\section{CASE REPORT}

A 51-year-old male patient sought medical attention complaining of pain for the past three months in the lower abdomen radiating to the right groin and inferior limb. More recently he referred watery diarrhea with up to three evacuations per day without blood or mucus accompanied by anorexia and weight loss of $20 \mathrm{~kg}$ during this period. Since the onset of the symptoms, he has been presenting depression. His medical history included the diagnosis of epilepsy, alcohol consumption for seven

a Department of Pathology - Faculdade de Medicina - Universidade de São Paulo, São Paulo/SP - Brazil.

Copyright $\odot 2012$ Autopsy and Case Reports - This is an Open Access article distributed of terms of the Creative Commons Attribution NonCommercial License (http://creativecommons.org/licenses/by/3.0/) which permits unrestricted non-commercial use, distribution, and reproduction in any médium provided article is properly cited. 
years in his youth, and smoking for a long period right up to the date of admission. On admission, the physical examination showed an emaciated patient, but ruddy, hydrated, acyanotic, and anicteric. Vital signs were within normal limits. Examination of the lungs, heart, abdomen, and lower limbs was unremarkable. The admission laboratory tests are presented in Table 1.

The endoscopic examination of the upper gastrointestinal tract and colon were normal. The chest x-ray (Figure 1) showed the presence of tiny nodules, diffusely distributed throughout both lungs.

During hospitalization, the patient developed worsening of the depression symptoms followed by an altered level of consciousness and attention deficit. He started presenting with a cough and respiratory distress. When rales were detected on the lungs, vancomycin and imipenem were started. Because of the elevated serum calcium levels he was treated throughout hospitalization with

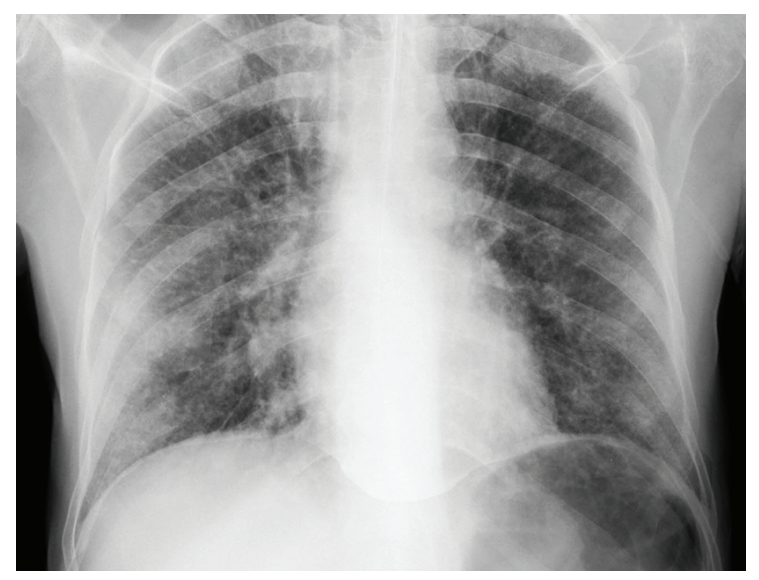

Figure 1 - Chest radiography showing diffuse bilateral nodules. parenteral hydration associated with furosemide and pamidronate. After 13 days of hospitalization, he developed signs of septicemia. He died without diagnosis of the underlying disease. An autopsy was performed.

\section{AUTOPSY FINDINGS}

On external examination, the anthropometric measures revealed the body of a man $176 \mathrm{~cm}$ in height, which weighed $47 \mathrm{~kg}$ (Body Mass Index = 15). The pancreas weighed $170 \mathrm{~g}(\mathrm{RV}=103-186 \mathrm{~g})$ and showed multiple grayish nodules, with up to $0.5 \mathrm{~cm}$ in diameter (Figure 2).

On light microscopy, there was a trabecular proliferation of cells with mild atypia displaying "salt and pepper chromatin" (Figure 3). The immunohistochemical panel revealed positivity for chromogranin, synaptophysin, cytokeratin

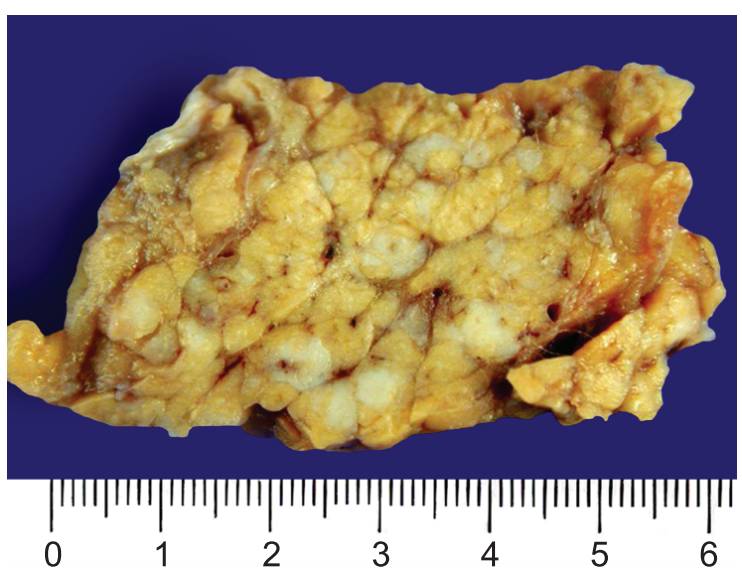

Figure 2 - Gross examination of the pancreas showing multiple grayish nodules measuring up to $0.5 \mathrm{~cm}$ in diameter spread throughout the organ.

Table 1 - Laboratory diagnostic work up at admission

\begin{tabular}{cccccc}
\hline Exam & Result & RV & Exam & Result & RV \\
\hline Hemoglobin & $13.7 \mathrm{~g} / \mathrm{dL}$ & $13.0-18.0 \mathrm{~g} / \mathrm{dL}$ & Creatinine & $0.58 \mathrm{mg} / \mathrm{dL}$ & $0.7-1.0 \mathrm{mg} / \mathrm{dL}$ \\
Hematocrit & $35.5 \%$ & $40.0-52.0 \%$ & BUN & $23 \mathrm{mg} / \mathrm{dL}$ & $10-50 \mathrm{mg} / \mathrm{dL}$ \\
Leukocytes & $9.16 .10^{3} / \mathrm{mm}^{3}$ & $4.0-11.10^{3} / \mathrm{mm}^{3}$ & Calcium & $12.5 \mathrm{mg} / \mathrm{dL}$ & $8.60-10.20 \mathrm{mg} / \mathrm{dL}$ \\
Neutrophils & $68.2 \%$ & $46-75 \%$ & $\mathrm{PTH}$ & $<3 \mathrm{pg} / \mathrm{mL}$ & $16-87 \mathrm{pg} / \mathrm{mL}$ \\
Eosinophils & $0.9 \%$ & $1-4 \%$ & $\mathrm{~K}^{+}$ & $2.1 \mathrm{mEq} / \mathrm{L}$ & $3.5-5.0 \mathrm{mEq} / \mathrm{L}$ \\
Basophils & $0.5 \%$ & $0-2.5 \%$ & $\mathrm{Na}^{+}$ & $132 \mathrm{mEq} / \mathrm{L}$ & $135-145 \mathrm{mEq} / \mathrm{L}$ \\
Lymphocytes & $22.0 \%$ & $18-40 \%$ & Glucose & $154 \mathrm{mEq} / \mathrm{L}$ & $70-99 \mathrm{mEq} / \mathrm{L}$ \\
Monocyte & $8.4 \%$ & $2-9 \%$ & AST & $22 \mathrm{U} / \mathrm{L}$ & $<37 \mathrm{U} / \mathrm{L}$ \\
Platelets & $356.10^{3} / \mathrm{mm}^{3}$ & $140-450.10^{3} / \mathrm{mm}^{3}$ & ALT & $26 \mathrm{U} / \mathrm{L}$ & $<41 \mathrm{U} / \mathrm{L}$ \\
\hline
\end{tabular}

ALT = alanine transaminase; $\mathrm{AST}=$ aspartate transaminase; BUN = blood urea nitrogen; Na+ = sodium; $\mathrm{K}+=$ potassium; $\mathrm{PTH}=$ parathyroid hormone; RV = reference value. 
35BH11, and focal positivity for glucagon and somatostatin (Figure 4). The immunohistochemistry for insulin, pancreatic polypeptide, and the specific transcription factor markers TTF-1 and CDX-2 were negative. The tumor cell proliferation, assessed by Ki67 antigen, was estimated at $3-20 \%$, which corresponds to the well-differentiated grade 2 of the WHO classification.

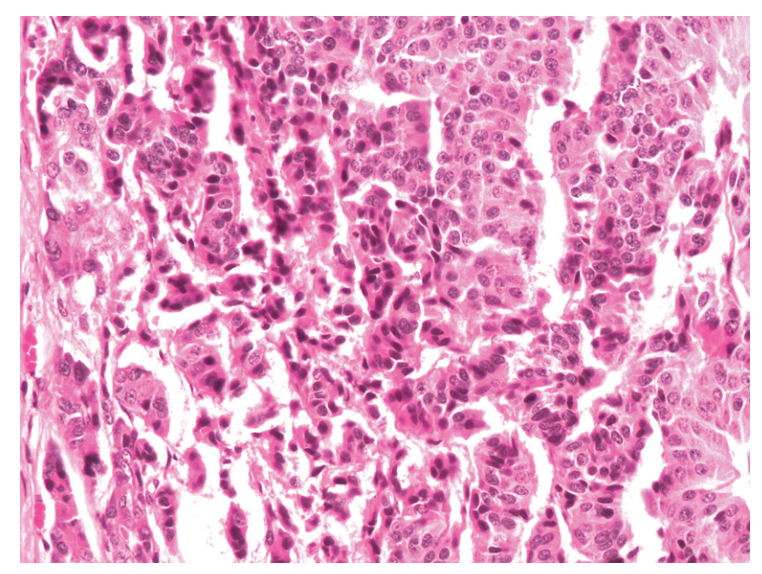

Figure 3 - Photomicrography of the pancreas showing trabecular proliferation of cells with mild atypia displaying "salt and pepper chromatin" (H\&E, 400x).
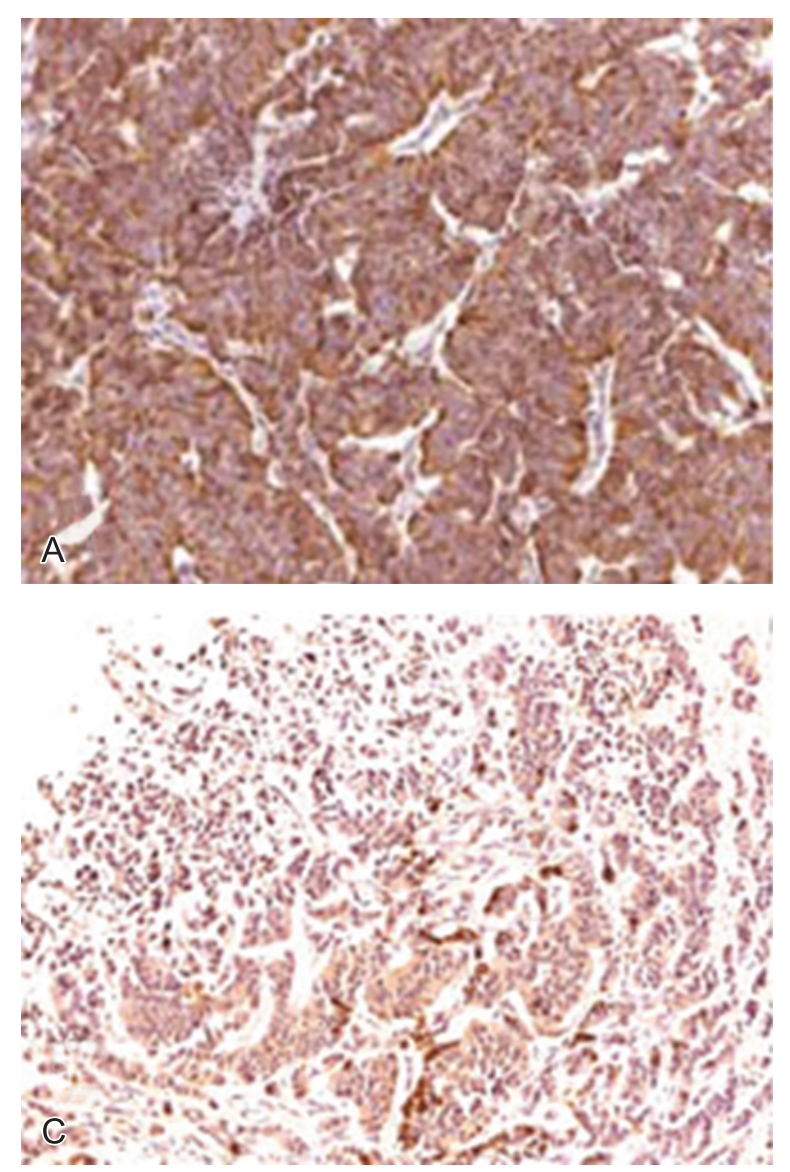

The right and left lungs weighed 670 $(\mathrm{RV}=360-570 \mathrm{~g})$ and $534 \mathrm{~g}(\mathrm{RV}=325-480 \mathrm{~g})$, respectively. Both lungs exhibited a gray and smooth external surface, with anthracotic deposits. The pleural surface showed multiple grayish nodules (Figure 5). On sectioning, the parenchyma was aerated and exhibited a spongy consistency. Reddish areas of consolidation were detected in both inferior lobes. No pleural effusion was detected. On histological examination, the grayish nodules corresponded to neuroendocrine tumors in the pleura as well as within the alveolar spaces, besides multiple areas of exudative pneumonia (Figure 6).

The microscopic examination of the spleen showed reactive splenitis. The heart weighted $354 \mathrm{~g}$ ( $R V=270-360 \mathrm{~g}$ ) and also showed multiple grayish nodules throughout the pericardial surface and within the myocardium (Figure 7).

The liver weight was normal and also presented multiple nodules in the parenchyma (Figure 8). The adrenals weighted $10 \mathrm{~g}$ each $(\mathrm{RV}=9.7$ each) and showed a yellowish cut surface with multiple grayish well-defined nodules
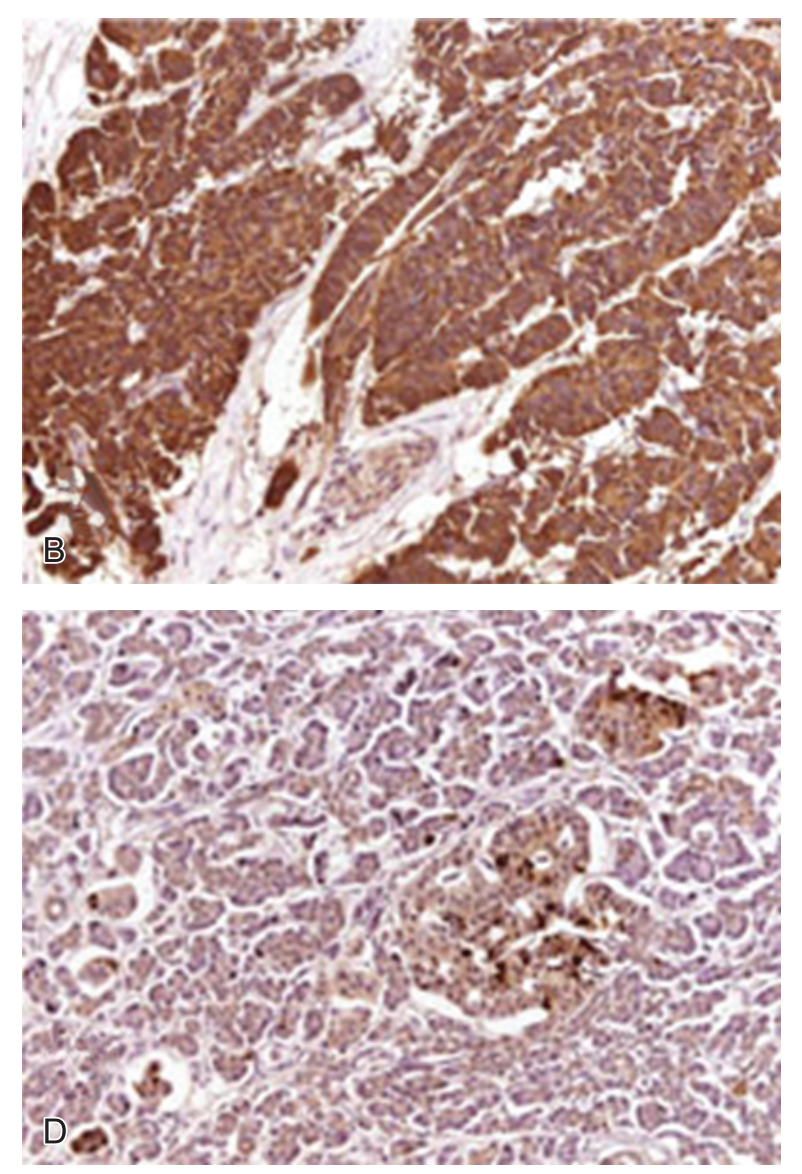

Figure 4 - Photomicrography of the pancreatic tumoral nodule. The immunohistochemical panel revealed positivity for chromogranin (A), synaptophysin (B), and focal positivity for glucagon (C) and somatostatin (D) (100x). 
(Figure 9). As well as the pancreas, the lungs, heart, liver, adrenals, thyroid, prostate, kidneys, and bone marrow showed microscopic neuroendocrine tumors on light microscopy. In the dorsum, the patient had a subcutaneous well-defined nodule, measuring $5.0 \mathrm{~cm}$ in its longest axis, which had a yellowish and homogeneous cut surface.

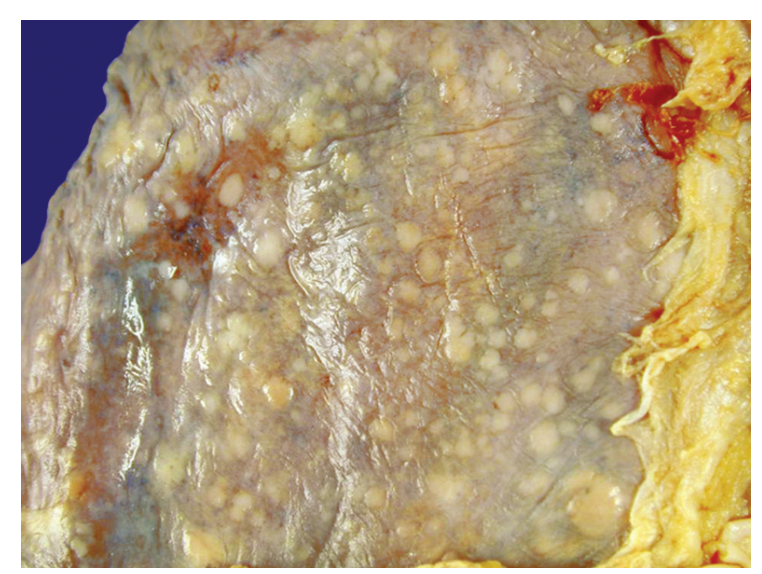

Figure 5 - Right pleural surface showing multiple grayish nodules.

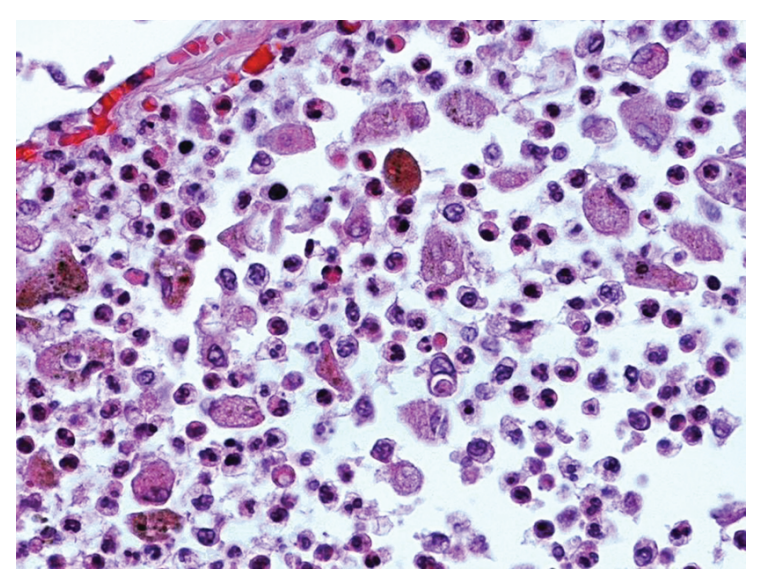

Figure 6 - Photomicrography of the lung showing areas of intra-alveolar exudative pneumonia (HE, 400x).
The histological examination revealed a lipoma with a neuroendocrine nodule within the adipose tissue, with the same histological characteristics of the tumor cited above. The clinical data added to the autopsy findings concluded that sepsis and pneumonia were the immediate cause of death.

\section{DISCUSSION}

The neuroendocrine system, a fascinating chapter of histology, is represented by scattered cells throughout the body identifiable by their reactivity for chromium and silver salts. Named as enterochromaffin cells, argentaffin cells, clear cells, enteroendocrine cells, and Kultschitsky cells by several investigators, they may give rise to the neuroendocrine neoplasm (NEN). In the $19^{\text {th }}$ century, Langhans (1867), Lubarsch (1888), and Ransom (1890) described tumors exhibiting neuroendocrine characteristics. $^{1}$ In 1907, Siegfried Oberndorfer coined the term karzinoide ("carcinoma-like" in German), to describe the feature of behaving like a benign tumor despite the microscopically malignant appearance. ${ }^{1}$ Even till now, the nomenclature is still under debate reflecting the heterogeneity of these tumors. ${ }^{2}$ Although the tumors are often slow growing, compared with adenocarcinomas, they can also be extremely aggressive. ${ }^{3}$

The incidence of NENs ranges from 2.5 to 5 cases per 100,000 in the Caucasian population. ${ }^{4}$ This has substantially increased over recent decades, partially due to improved diagnostic techniques and clinical awareness. ${ }^{5-8}$
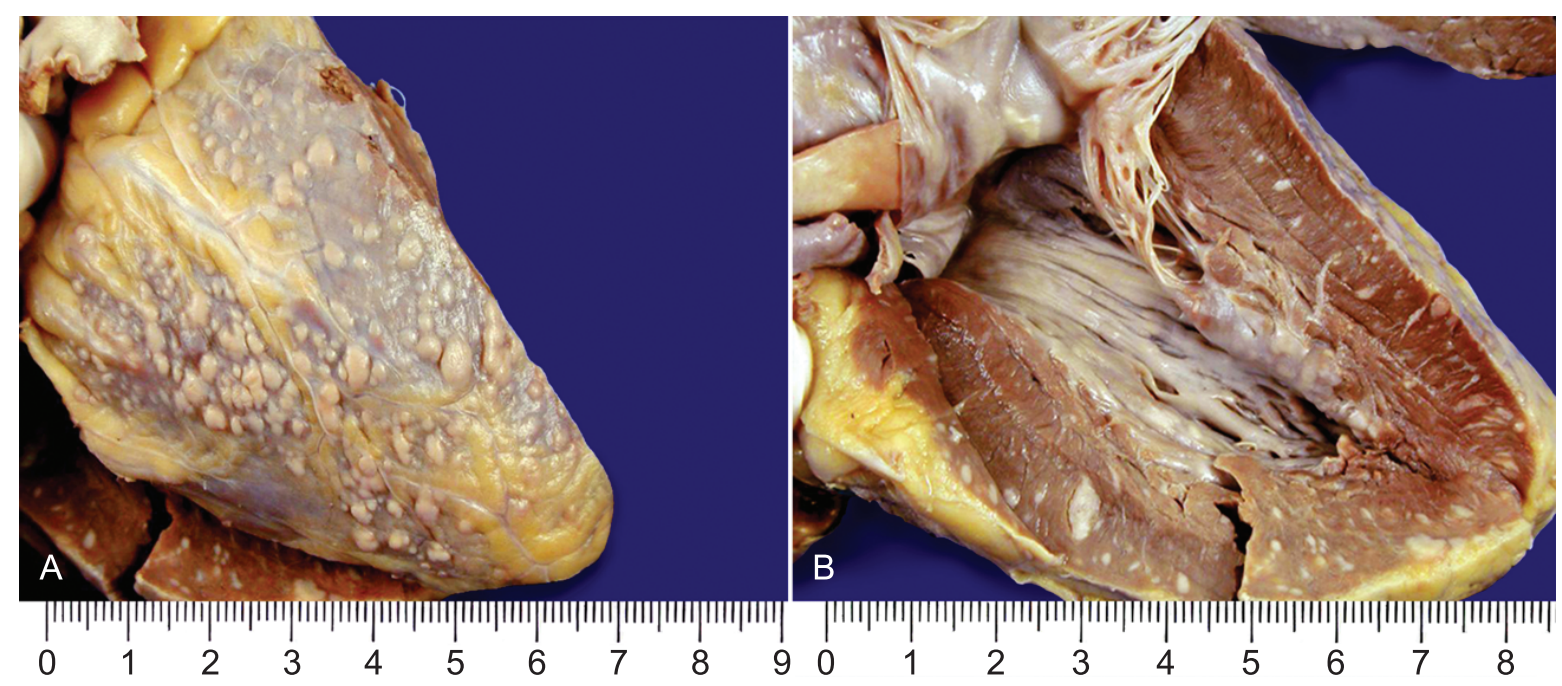

Figure 7 - Gross examination of the heart showing multiple grayish nodules throughout the pericardial surface and within the myocardium. 
NENs seem to be homogeneous in terms of morphology, but depending on their localization, these neoplasms reveal distinct phenotypes with respect to pathology, immunohistochemistry, and hormonal syndromes. ${ }^{9}$ They may develop in almost any organ of the abdomen, thorax, neck, and skin. The most commonly observed sites of NEN are the lungs and the gastroenteropancreatic system (GEP), where more than 50 entities have been observed. ${ }^{10}$ There are rare sites of occurrence, which include the larynx, thymus, thyroid, adrenal, gonads, kidney. ${ }^{11,12}$ The incidence of primary site may vary with gender and race..$^{5}$ In the National Cancer Institute (USA) survey, from 1950 until 1999, 13,715 cases were retrieved. The incidence of gastrointestinal (GI) NEN was $67.5 \%$ and bronchopulmonary $25.3 \%$. Within the GI-NEN $41.8 \%$ were localized in the small intestine, $27.4 \%$ in the rectum, and $8.7 \%$ in the stomach. ${ }^{12} \mathrm{~A}$ cohort study conducted in southern Spain ${ }^{4}$ comprised 837 patients and 907 GEP-NET tumors. In this study, gastrointestinal sites represented $55 \%$ of cases followed by nonfunctional pancreatic tumors $(20 \%)$. Among the functional tumors, the enteric

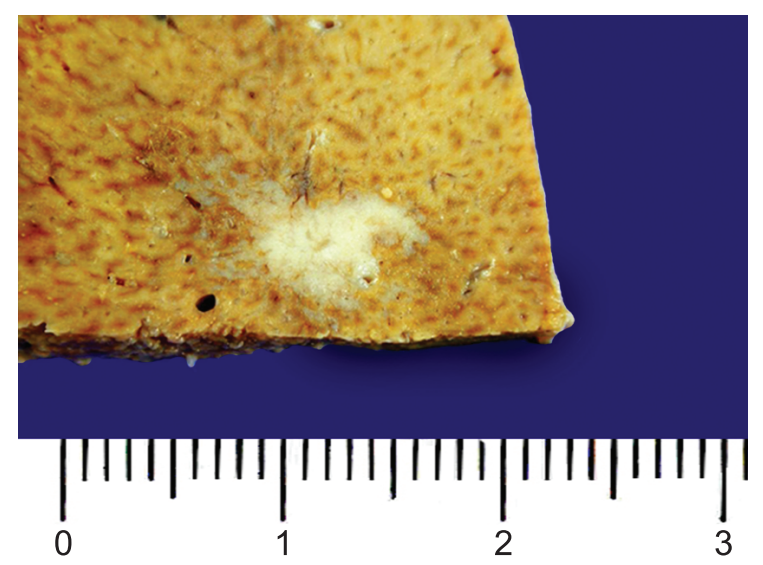

Figure 8 - Gross examination of the liver presenting nodules in the parenchyma.

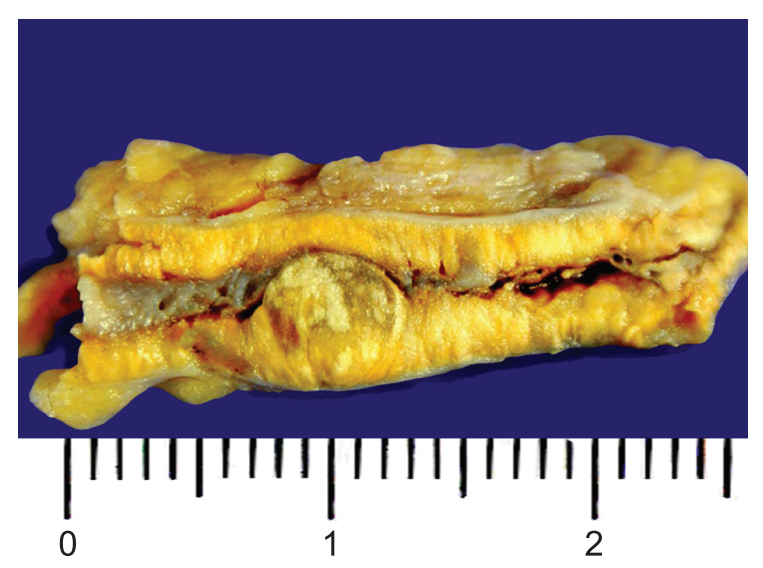

Figure $\mathbf{9}$ - Gross examination of the right adrenal gland, showing a yellowish cut surface with multiple grayish well-defined nodules.
NEN (10\%), insulinomas (8\%), and gastrinomas $(4 \%)$ were the most common. Glucagonoma, VIPoma, and somatostatinoma totaled less than $2 \%$. In this study, $44 \%$ of patients presented with widespread disease at the time of diagnosis, which is different from the North American series where $12.9 \%$ of patients showed this stage at the time of diagnosis. ${ }^{12}$ The patient reported in this case study presented a widespread and advanced-stage disease, evidenced by the necropsy findings and clinically by the cachexia that became symptomatic three months before medical attention.

Neuroendocrine carcinoma of unknown primary (NCUP) accounts for $9-13 \%$ of all NEN, and $5 \%$ of all malignant neoplasm. ${ }^{4,5,13}$ These tumors arise from an occult or clinically undetectable primary site, which can be located in the liver, bronchus, pancreas, colon, rectum, or elsewhere. Two different clinicopathologic subsets of these tumors have been described. The first subset includes low-grade neuroendocrine carcinomas (metastatic well-differentiated NEN) usually involving the liver or presenting with symptoms due to the secretion of vasoactive peptides (functional tumors). This subset of tumors presents an indolent behavior. The second subset includes high-grade poorly differentiated carcinomas, which present rapidly growing biological behavior. ${ }^{2}$ It cannot be identified if these tumors arise from an occult primary gastrointestinal or pulmonary site or even from multipotent stem cells. ${ }^{13}$ The tumor presented in this case study belongs to the first group, with a proliferation cell index classified as G2. Unfortunately, the available immunohistochemical panel could not precisely elucidate the primary tumor, but in accordance with the available results and the literature data the tumor most probably belongs to the GEP-NEN group.

The WHO classification of 2010 presumes that all NEN are potentially malignant, but differs markedly in respect of their likelihood to develop metastases. The classification takes into account the tumor proliferative activity measured by immunostaining for the cell cycle-dependent marker Ki67 antigen, and/or by number of mitoses per unit area of tumor (usually expressed as mitoses per 10 high-power microscopic fields or $2 \mathrm{~mm}^{2}$ ). ${ }^{14}$ Therefore the tumor is distinguished between well-differentiated and poorly differentiated neoplasms. ${ }^{15-17}$ All welldifferentiated neoplasms, graded G1 (Ki67 < 2\%) and G2 (Ki67 2-20\%), regardless of their biological behavior, will be called neuroendocrine tumors (NETs). All poorly differentiated neoplasms, graded G3 (Ki67 > 20\%), will be termed neuroendocrine 
carcinomas (NECs). ${ }^{17,18}$ The WHO classification for lung and thymus NETs relies only on the mitotic rate, ${ }^{19}$ whereas the European Neuroendocrine Tumor Society (ENETS) as well as the WHO recommend either mitotic rate or Ki67 labeling index for gastroenteropancreatic NETs. ${ }^{20}$

The NEN histopathological workup includes the use of the neurosecretory markers, chromogranin $\mathrm{A}(\mathrm{CgA})$ and synaptophysin. $\mathrm{CgA}$ is part of the membrane of neurosecretory hormone granules, and its positivity depends on the number of these intracellular granules being evident in the well-differentiated tumors while mild reactions are observed in the poor-differentiated, due to the scarcity of granules in these tumor cells. CgA may even lack in NEN of the lung and rectum. Synaptophysin, on the other hand, can be demonstrated in all NEN, independently of the number of neurosecretory vesicles. ${ }^{10}$

The search for hormones, biogenic amines, and transcription factors is useful in identifying the primary tumor in the case of metastases of unknown origin. In this setting among the GEP system, the vesicular monoamine transporter 2 (VMTA2) is a marker for enterochromaffin-like cells of the stomach. It can be positive also in the adrenal medulla and paraganglia cells. NEN in the duodenum commonly produces gastrin and somatostatin. Serotonin-forming NEN is predominant in the ileum and appendix. Pancreatic NEN primarily produces insulin, glucagon, pancreatic polypeptide, and somatostatin, as well as calcitonin, adrenocorticotropic hormone (ACTH) or vasoactive intestinal polypeptide (VIP). VIP can also be found in adrenal NEN, such as pheochromocytoma. These peptide hormones may be revealed by immunohistochemistry; however, these positive reactions are not necessarily correlated with endocrine syndromes. ${ }^{21,22}$ The immunohistochemical research of this case allowed the diagnosis of a NEN through the positivity to $\mathrm{CgA}$ and synaptophysin. The focal positivity to glucagon and somatostatin enabled the localization of the tumor as being identified from the GEP system. Although classified as well differentiated, the grade 2 NETs may fail to express strong positive immunohistochemical reactions for specific markers. The evidence of specific transcription factors is also noteworthy for the determination of the primary GEP-NEN. In this context, CDX-2 is positive in $90 \%$ of NEN in the ileum and appendix; Islet-1 is highly specific for pancreas; TTF-1 is expressed in about $50 \%$ of bronchopulmonary NEN. ${ }^{10,22}$ In the case reported here, the immunostaining was negative for both CDX-2 and TTF-1.

A primary neuroendocrine tumor originating from the skin (Merkel cell carcinoma) is unlikely since the tumor cells were small and well differentiated.

The clinical picture of NEN depends on its primary tumor, the presence of metastases, and the production of hormones or peptide of clinical significance. Among the latter are the insulinoma, glucagonoma, gastrinoma, somatostatinoma, VIPoma, thymic producing ACTH tumors, and others.

In a series of 241 patients with the diagnosis of GEP-NEN, the most common symptoms were abdominal pain $(29.5 \%)$, diarrhea $(8.7 \%)$, weight loss $(7.5 \%)$, gastrointestinal bleeding $(5.4 \%)$, flushing $(3.7 \%)$, and bowel obstruction (3.3\%). In this series, neurological and psychiatric symptoms were reported in $2.1 \%$ of patients, among whom $9.1 \%$ presented pancreatic NENs. Diarrhea can be the manifestation of the carcinoid syndrome, which is most prevalent in the GEP-NEN and some tumors of the bronchopulmonary origin. The syndrome becomes evident when metastases are present. The diarrhea in these cases occurs due to the overproduction of serotonin by the tumor, which is responsible for the bowel hypermotility and intestinal mucosa hypersecretion. The patient of this case study featured a history with few clinical data, but abdominal pain, diarrhea, weight loss, and a depressed mood were present. The diarrhea could be part of a carcinoid syndrome, even in the absence of the other carcinoid syndrome symptoms. Diarrhea can also be observed in glucagonoma, but is often associated with diabetes mellitus and the presence of necrolytic migratory erythema (involving the face, perineum, or extremities), which were lacking in this case. The somatostatinoma also present diarrhea, but diabetes mellitus, again, was also present. The VIPoma that present clinically with watery diarrhea associated with hypokalemia, hypercalcemia, and eventually hyperglycemia could be a likely diagnosis for this case once the electrolytic disturbances were present. Tumors producing calcitonin are not usually associated with hypercalcemia, unless bone metastases are present.

The laboratory diagnostic workup in functional NEN may include the hormonal dosages (gastrin, insulin, peptide $\mathrm{C}$, somatostatin, pancreatic polypeptide, glucagon, ACTH, cortisol, VIP and urinary 5-hydroxy-indol-acetic acid (5HIAA), 
depending on the functional status of the tumor, clinical symptoms, and histological features. ${ }^{23}$ Even with respect to the diagnosis, the computed tomography scan of the chest, abdomen, and pelvis complemented by somatostatin receptor scintigraphy (SRS) are indicated. Over 90\% of gastroenteropancreatic NENs, including nonfunctioning islet cell tumors and carcinoids, have high concentrations of somatostatin receptors, and can be imaged using octreotide, a radiolabeled form of the somatostatin analog. SRS has also been used to help provide information regarding the primary tumor location. The endoscopic examination is fundamental for the diagnosis of NEN, which is included for the determination of the primary tumor in case of liver metastasis. ${ }^{23-25}$ Unfortunately, in this case study, this investigation was not undertaken because of the lack of clinical suspicion of NEN and the short period of hospitalization.

\section{REFERENCES}

1. Rosai J. The origin of neuroendocrine tumors and the neural crest saga. Mod Pathol. 2011;24:S53-7. PMid:21455201. http://dx.doi.org/10.1038/modpathol.2010.166

2. Stoyianni A, Pentheroudakis G, Pavlidis N. Neuroendocrine carcinoma of unknown primary: A systematic review of the literature and a comparative study with other neuroendocrine tumors. Cancer Treat Rev. 2011;37:358-65 PMid:21481536. http://dx.doi.org/10.1016/j.ctrv.2011.03.002

3. Gustafsson BI, Kidd M, Modlin IM. Neuroendocrine tumors of the neuroendocrime system. Curr Opin Oncol. 2008;20:112. PMid:18043250. http://dx.doi.org/10.1097/ CCO.0b013e3282f1c595

4. Garcia-Carbonero R, Capdevila J, Crespo-Herrero G, et al. Incidence, patterns of care and prognostic factors for outcome of gastroenteropancreatic neuroendocrine tumors (GEPNETs): results from the National Cancer Registry of Spain (RGETNE). Ann Oncol. 2010;21:1794-803. PMid:20139156. http://dx.doi.org/10.1093/annonc/mdq022

5. Yao JC, Hassan M, Phan A, et al. One hundred years after "carcinoid": epidemiology of and prognostic factors for neuroendocrine tumors in 35,825 cases in the United States. J Clin Oncol. 2008;26:3063-72. PMid:18565894. http://dx.doi.org/10.1200/JCO.2007.15.4377

6. Hauso O, Gustafsson BI, Kidd M, et al. Neuroendocrine tumor epidemiology: contrasting Norway and North America. Cancer. 2008;113:2655-64. PMid:18853416. http://dx.doi. org/10.1002/cncr.23883

7. Hemminki K, Li X. Incidence trends and risk factors of carcinoid tumors: a nationwide epidemiologic study from Sweden. Cancer. 2001;92:2204-10. http://dx.doi.
org/10.1002/1097-0142(20011015)92:8<2204::AIDCNCR1564>3.0.CO;2-R

8. Lepage C, Rachet B, Coleman MP. Survival from malignant digestive endocrine tumors in England and Wales: a population-based study. Gastroenterology. 2007;132:899-904. PMid:17383419. http://dx.doi.org/10.1053/j.gastro.2007.01.006

9. Klöppel G. Tumour biology and histopathology of neuroendocrine tumours. Best Pract Res Clin Endocrinol Metab. 2007;21:15-31. http://dx.doi.org/10.1016/j. beem.2007.01.004

10. Anlauf M. Neuroendocrine neoplasms of the gastroenteropancreatic system: pathology and classification. Horm Metab Res. 2011;43:825-31. PMid:22105474. http:// dx.doi.org/10.1055/s-0031-1291307

11. Ferolla $P$, Faggiano A, Avenia F, et al. Epidemiology of non-gastrtroenteropancreatic (neuro)endocrine tumors. Clin Endocrinol. 2007;66:1-6.

12. Modlin IM, Lye KD, Kidd M. A 5-decade analysis of 13715 carcinoid tumors. Cancer. 2003;97:934-59 PMid:12569593. http://dx.doi.org/10.1002/cncr.11105

13. Spigel DR, Hainsworth JD, Greco FA. Neuroendocrine carcinoma of unknown primary site. Semin Oncol. 2009;36:529. PMid:19179188. http://dx.doi.org/10.1053/j. seminoncol.2008.10.003

14. Klimstra D, Modlin IR, Coppola D, Lloyd RV, Suster S. The pathologic classification of neuroendocrine tumors. A review of nomenclature, grading, and staging systems. Pancreas 2010;39:707-12. PMid:20664470. http://dx.doi. org/10.1097/MPA.0b013e3181ec124e

15. Solcia E, Klöppel G, Sobin LH, editors. Histological typing of endocrine tumors. 2nd ed. Berlin: Springer; 2000. WHO international histological classification of tumors.

16. Heitz PU, Komminoth P, Perren A, et al. Pancreatic endocrine tumours: introduction. In: DeLellis R A, Lloyd RV, Heitz PU, Eng C, editors. Pathology and genetics: tumours of endocrine organs. WHO classification of tumors. Lyon: IARC Press; 2004. p. 177-82.

17. Rindi G, Arnold R, Bosman FT, et al. Nomenclature and classification of neuroendocrine neoplasms of the digestive system. In: Bosman FT, Carneiro F, Hruban RH, Theise ND, editors. WHO classification of tumors of the digestive system. Lyon: IARC Press; 2010. p. 13-4.

18. Klöppel G. Classification and pathology of gastroenteropancreatic neuroendocrine neoplasms. Endocr Relat Cancer. 2011;18:S1-16. PMid:22005112. http://dx.doi. org/10.1530/ERC-11-0013

19. Travis WD. The concept of pulmonary neuroendocrine tumours. In: Travis WD, Brambilla E, Muller-Hermelink HK, Harris CC, editors. Pathology and genetics of tumours of the lung, pleura, thymus and heart. Lyon, France: IARC Press; 2004. p. 19-20. 
20. Bosman F, Carneiro F, Hruban R, Theise N, editors. WHO Classification of tumours of the digestive system. Lyon: IARC Press; 2010.

21. Klöppel G, Anlauf M. Epidemiology, tumour biology and histopathological classification of neuroendocrine tumours of the gastrointestinal tract. Best Pract Res Clin Gastroenterol. 2005;19:507-17. http://dx.doi.org/10.1016/j. bpg.2005.02.010

22. Klöppel G, Rindi G, Anlauf M, Perren A, Komminoth P. Sitespecific biology and pathology of gastroenteropancreatic neuroendocrine tumors. Virchows Arch. 2007;451:9-27. PMid:17684761. http://dx.doi.org/10.1007/s00428-007-0461-0
23. Oberg K. Diagnostic work-up of gastroenteropancreatic neuroendocrine tumors. Clinics. 2012;67:109-12. http:// dx.doi.org/10.6061/clinics/2012(Sup01)18

24. Wong KK, Waterfield RT, Marzola MC, et al. Contemporary nuclear medicine imaging of neuroendocrine tumours. Clin Radiol [Internet]. 2012 May 23; [Epub ahead of print; cited 2012 July 25]. Available from: http://www.sciencedirect. com/science/article/pii/S0009926012001687

25. Lamberts SW, Bakker WH, Reubi JC, Krenning EP. Somatostatin-receptor imaging in the localization of endocrine tumors. N Engl J Med. 1990;323:1246. PMid:2170840. http:// dx.doi.org/10.1056/NEJM199011013231805

\section{Conflict of interest: None}

Submitted on: $11^{\text {th }}$ April 2012

Accept on: $1^{\text {st }}$ August 2012

Correspondence: Department of Pathology

Faculdade de Medicina, Universidade de São Paulo, São Paulo/SP - Brazil

E-mail: frederico.bribeiro@gmail.com 